\section{Parálisis general sifilítica: presentación de 5 casos}

\author{
ARCHIBALDO DONOSO S. ${ }^{1}$, RICARDO URZÚA ${ }^{1}$, \\ ANDREA SLACHEVSKY CH. ${ }^{2}$, CARLOS SILVA R. ${ }^{1}$
}

\section{Paretic neurosyphilis: report of five patients}

We report five male patients, aged 35 to 63 years who suffered from paretic neurosyphilis. The clinical course was that of a subacute dementia with a frontal syndrome, with more apathy than euphoria. All were HIV negative and four were heterosexual. In all, the cerebrospinal fluid had a mononuclear pleocytosis and a positive VDRL. EEG was abnormal in the 3 cases in whom it was performed. One patient in whom a brain angiography was performed, had images of vasculitis. Treatment with 18-24 million units of penicillin per day during two weeks or more, was partially effective.

(Rev Med Chile 2012; 140: 625-628).

Key words: Dementia; Neurosyphilis; Vasculitis, Central Nervous System.

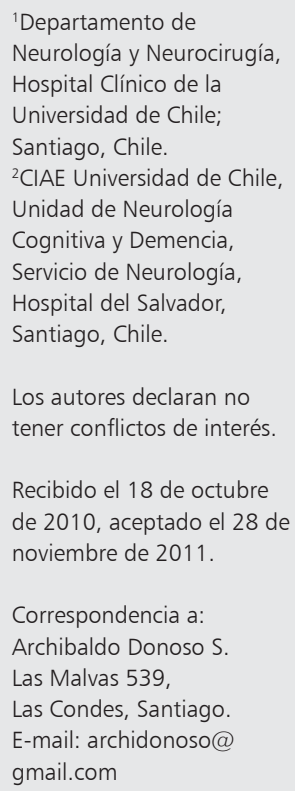

L a neurosífilis fue la gran patología neurológica hasta la primera mitad del siglo XX ${ }^{1}$. Se creyó que iba a desaparecer con la penicilina, pero ha persistido e incluso aumentado, asociada al $\mathrm{VIH}^{2,3}$. La etapa terciaria, con años de latencia, se caracteriza por lesiones esqueléticas, aórticas y del sistema nervioso central ${ }^{1,4}$. Este último puede ser una sífilis meningovascular, parálisis general (PG), tabes dorsal, atrofia óptica, paquimeningitis hipertrófica espinal, y el goma $^{1,4,5}$. Para la etapa terminal Calmeil acuñó el término "paralysie genérale des alienés" ya que existía pérdida global de capacidades físicas y mentales y fallecían por inanición o sepsis ${ }^{6}$. En Chile existen publicaciones sobre neurosífilis, pero no centradas en la $\mathrm{PG}^{2,3,7,8}$.

Para diagnosticar demencia debe existir un deterioro significativo de 2 o más capacidades cognitivas (memoria, capacidad ejecutiva, lenguaje, etc.), y que el cuadro clínico persista durante 6 meses o más, para excluir un compromiso de conciencia prolongado ${ }^{9,10}$. Sin embargo, se acepta la existencia de "demencias subagudas" que se instalan en semanas o meses y cuyos límites con un estado confusional es impreciso ${ }^{4}$. Este grupo incluye variadas patologías: tumores, lesiones vasculares, hematomas subdurales, encefalopatías tóxicas o metabólicas, cuadros desmielinizantes, hidrocefalia, infecciones (Jacob-Creutzfeldt, VIH y otras, entre las cuales está la PG), etc. A veces una patología psiquiátrica puede simular una demencia ${ }^{11}$. El diagnóstico preciso requiere evaluación clínica, neuropsicológica, de laboratorio y de imágenes cerebrales. El estudio de vitamina B12 y ácido fólico, perfil tiroideo y VDRL, discutible en demencias crónicas, es indispensable en demencias subagudas.

La PG es una encefalitis de curso subagudo o crónico por Treponema pallidum. El 5\% de los casos de sífilis primaria, sin tratamiento, puede llegar a ella en 10 a 25 años $^{1,5}$. El cerebro muestra atrofia, engrosamiento e infiltrado inflamatorio de meninges, inflamación perivascular, pérdida de neuronas y gliosis; estas alteraciones predominan en la corteza frontal y temporal ${ }^{1,5}$. En el $40-50 \%$ de los casos se encuentra el treponema en la corteza. Se instala progresivamente en semanas o meses, con cambios de personalidad (descuido, pérdida o descontrol de iniciativa, labilidad emocional, fatigabilidad), pérdida de memoria y juicio, cuadros psicóticos ${ }^{1,5,6}$. Puede encontrarse temblor, disartria, hiperreflexia, signo de Babinski y alteraciones pupilares (pupila del Argyll-Robertson); a veces existe epilepsia. Sin tratamiento fallecen postrados en pocos años. En ocasiones se asocia compromiso medular y se habla de "tabo-parálisis". 
En esta publicación nos interesa destacar que la PG no ha desaparecido y debe ser considerada entre las demencias subagudas, especialmente si existe una disfunción frontal o disejecutiva, con predominio de alteraciones conductuales y respeto relativo de la memoria, a diferencia de la enfermedad de Alzheimer ${ }^{12}$.

\section{Presentación de los casos}

Los casos fueron recolectados en forma retrospectiva y se presentan en la Tabla 1; sólo se detalla el último. Eran hombres de edad media, 4/5 heterosexuales, todos VIH negativos. Presentaron un síndrome frontal subagudo; en 3 casos destacó la

Tabla. Resumen de los casos de parálisis general

\begin{tabular}{|c|c|c|c|c|c|}
\hline Caso & 0 - 1986 & N - 1998 & $T-2003$ & R - 2007 & W - 2009 \\
\hline Sexo & M & M & M & $\mathrm{M}$ & M \\
\hline Edad (años) & 50 & 63 & 49 & 57 & 35 \\
\hline Escolaridad (años) & 6 & 8 & 12 & 12 & 15 \\
\hline Conducta sexual & homosex & heterosex & heterosex & heterosex & heterosex \\
\hline $\mathrm{VIH}$ & $(-)$ & $(-)$ & $(-)$ & $(-)$ & $(-)$ \\
\hline $\begin{array}{l}\text { Factores de riesgo } \\
\text { vascular }\end{array}$ & Sí & No & Sí & No & No \\
\hline Infartos cerebrales & AIT & No & Sí & No & No \\
\hline Inicio subagudo & meses & meses & meses & semanas & meses \\
\hline Sintomas iniciales & $\begin{array}{l}\text { Olvidos, somno- } \\
\text { lencia, apatía, } \\
\text { autoscopia, AlT. }\end{array}$ & $\begin{array}{l}\text { Olvidos, euforia, } \\
\text { torpeza motora }\end{array}$ & $\begin{array}{l}\text { Mareos, des- } \\
\text { ánimo, atrofia } \\
\text { óptica leve }\end{array}$ & $\begin{array}{l}\text { Euforia, ideas de- } \\
\text { lirantes, olvidos, } \\
\text { descuido. }\end{array}$ & $\begin{array}{l}\text { Apatía, olvidos, } \\
\text { disartria, labili- } \\
\text { dad emocional }\end{array}$ \\
\hline Compromiso motor & piramidal leve & piramidal leve & no & piramidal leve & ataxia leve, tics \\
\hline Pupilas & $\mathrm{N}$ & Argyll-Robertson & anisocoria & $\mathrm{N}$ & $N$ \\
\hline Retención orina & No & No & Sí & No & Sí \\
\hline Sd.frontal & Apático & Euforia & Apático & Apático/euforia & Apático \\
\hline lenguaje & $\begin{array}{l}\text { Af. Wernicke } \\
\text { laconismo }\end{array}$ & $\mathrm{N}$ & $\begin{array}{l}\text { Disartria, laco- } \\
\text { nismo }\end{array}$ & $\mathrm{N}$ & $\begin{array}{l}\text { Laconismo, af. } \\
\text { Broca }\end{array}$ \\
\hline Atención & Falla & Falla & Falla & Falla & Falla \\
\hline Memoria episódica & Sd. Korsakoff & Amnesia & Sd. Korsakoff & Amnesia & Amnesia \\
\hline MM & -- & -- & 26 & 28 & 9 \\
\hline FAB & -- & -- & 8 & 9 & 3 \\
\hline LCR inflamatorio & Sí, 119 cels & Sí, 42 cels & Sí, 10 cels & Sí, 12 cels & Sí,130 cels \\
\hline EEG & Foco lento izq & -- & -- & Lento & $\begin{array}{l}\text { Foco lento irri- } \\
\text { tativo }\end{array}$ \\
\hline VDRL sangre & $(+)$ & $(+)$ & $(--)$ & $(+)$ & $(+)$ \\
\hline Imagen cerebral & $\begin{array}{l}\text { TC atrofia pred } \\
\text { izq }\end{array}$ & TC atrofia & $\begin{array}{l}\text { TC infartos, } \\
\text { microangiop }\end{array}$ & TC normal & $\begin{array}{l}\text { RM atrofia FT } \\
\text { izq. }\end{array}$ \\
\hline angiografía & -- & -- & vasculitis? & -- & -- \\
\hline Tratamiento penicilina & Sí & Sí & Sí & Sí & Sí \\
\hline Secuelas & Sd. frontal & Sd. frontal & $\begin{array}{l}\text { Sd. frontal } \\
\text { apático }\end{array}$ & $\begin{array}{l}\text { Sd. frontal, } \\
\text { delirio }\end{array}$ & $\begin{array}{l}\text { Sd. frontal } \\
\text { apático }\end{array}$ \\
\hline
\end{tabular}

M: masculino; AIT: ataque isquémico transitorio; MM: Minimental test de Folstein; FAB: Frontal assessment battery; N: Normal; Af: afasia; --: no precisado; TC: tomografía computada cerebral; RM: resonancia magnética cerebral 
apatía, en los otros el ánimo subido. Todos tenían amnesias y 2 un síndrome de Korsakoff. En 3 existían signos piramidales discretos; en 2 retención de orina, en uno de ellos asociado a ataxia. Cuando se aplicaron las pruebas Minimental test de Folstein $(\mathrm{MM})$, que mide la eficiencia cognitiva global, y Frontal Assessment Battery (FAB), que evalúa las funciones frontales, el mayor compromiso de esta confirmó el síndrome disejecutivo. En 3 existía laconismo con o sin afasia. Dos casos con episodios de isquemia cerebral tenían factores de riesgo vascular.

El líquido cefaloraquídeo (LCR) fue siempre inflamatorio y con VDRL reactivo; en uno la serología en sangre fue negativa. El electroencefalograma (EEG) estuvo alterado en $3 / 3$ casos; en cambio las imágenes estructurales no siempre fueron anormales. En el caso T una angiografía (indicada por un infarto cerebral en un hombre joven con VDRL no reactivo en sangre y antes del estudio de LCR) fue compatible con vasculitis. Todos recibieron altas dosis de penicilina sódica ev, pero la mejoría fue parcial y quedaron con secuelas cognitivas.

W tenía 35 años, era supervisor de ventas, soltero; sin antecedentes de importancia salvo ser promiscuo; fumaba y bebía poco, no consumía drogas. En el $2^{\circ}$ semestre de 2008 aparecieron tendencia a aislarse, olvidos, insomnio, pérdida de libido, disartria, cefaleas. Existía una mezcla de labilidad emocional y apatía. Perdió su trabajo en abril de 2009. En mayo un psiquiatra lo derivó a neurólogo, quien pidió una batería de exámenes, entre ellos VDRL en sangre que fue reactivo. El examen general era normal. Se mostraba alerta y colaboraba al examen; destacaban un síndrome frontal y una afasia no fluente mixta. Existían nistagmo en miradas extremas, paramimesis, enganche digital, tics de elevación de hombros. Una discreta ataxia de la marcha, arreflexia tendinosa de miembros inferiores y una retención de orina configuraban una tabes dorsal.

El síndrome frontal se expresaba en apatía, abulia y conducta de imitación. Fue incapaz de comprender escenas complejas y de interpretar proverbios; perseveraba con frecuencia. Tenía defectos atencionales (cálculo, retención de cifras, inversión de series automáticas) y existía una afasia no fluente mixta. En MM obtuvo 9/30 puntos, en FAB 3/18 puntos; fue incapaz de abstraer. Rindió mejor en Matrices Progresivas Coloreadas (MPC,
25/36 puntos) y en la prueba de asociación semántica del $4^{\circ}$ excluido (acertó en $7 / 8$ ensayos). No existían agnosias visuales ni espaciales, apraxia constructiva, ideatoria, ideomotora ni del vestir. Tampoco tenía agnosia digital ni desorientación derecha-izquierda.

El LCR mostró pleocitosis (130 mononucleares, $88 \%$ de linfocitos, $10 \%$ de polinucleares y $2 \%$ de monocitos), glucosa $21 \mathrm{mg} / \mathrm{dL}$ y proteínas 180 $\mathrm{mg} / \mathrm{dL}$. El VRDL fue reactivo 1/128. La resonancia magnética $(\mathrm{RM})$ cerebral mostró atrofia de predominio frontotemporal izquierdo, y el EEG actividad irritativa y lenta en la misma zona. La serología para VIH fue negativa, y otros exámenes humorales fueron normales (función hepática, coagulación, hemograma y VHS, nivel de vitamina B12, Na, $\mathrm{K}$ y Cl, perfil bioquímico, proteína $\mathrm{C}$ reactiva, PCR para virus herpes simple en LCR).

Se trató con penicilina sódica 4.000 .000 ui ev c/4 horas durante 15 días, betametasona $4 \mathrm{mg}$ ev c/8 horas por 3 días y fenitoina $100 \mathrm{mg}$ c/8 horas. El tratamiento fue bien tolerado y parcialmente eficaz. A comienzos de 2010 el examen neurológico básico era normal, en MM obtuvo 28/30 puntos, en MPC 31/36, en FAB 13/18. Persistía un síndrome frontal, con actitud pueril, fallas de juicio y de coherencia del discurso. El LCR era normal, con serología reactiva a $1 / 32$, lo que unido a la aparición de crisis convulsivas llevó a un segundo tratamiento con penicilina, de 21 días, y a indicar ácido valproico en vez de fenitoína. Fue jubilado por invalidez y vive con sus padres.

\section{Comentarios}

La demografía de nuestros casos es similar a la publicada: la mayor incidencia de PG se encuentra entre los 40 y 50 años, es mayor en hombres VIH $(-)^{13-16}$. Se ha planteado que la reaparición de la neurosífilis se debe en parte a la pandemia por VIH y que en estos casos la evolución es más rápida y con menos respeto de las etapas que en los inmunocompetentes ${ }^{2,3,15}$. Sin embargo, en pacientes VIH $(+)$ suele ser asintomática o ser una neurosífilis secundaria (meningitis, otolúes, compromiso ocular, sífilis meningovascular); a pesar de evolucionar más rápidamente no llega a las formas tardías (tabes dorsal, PG) ${ }^{2}$. Nuestros 5 casos fueron VIH (-) y lo mismos sucedió en otras series recientes de parálisis general ${ }^{14,15}$. En una 
serie nacional de pacientes portadores o no del $\mathrm{VIH}$, el único caso de demencia era VIH (-) $)^{3}$. En una serie india, sólo 2 de 25 casos de neurosífilis eran VIH (+); 5 tenían una demencia y aunque el autor no fue explícito probablemente eran VIH $(-)^{17}$. La detección de la neurosífilis es más precoz en pacientes $\mathrm{VIH}(+)$, en quienes se realiza VDRL en forma regular y si es reactivo se procede a un estudio del LCR $3,5,15$.

Los principales exámenes complementarios son el LCR y las imágenes cerebrales. El LCR generalmente muestra una moderada pleocitosis y aumento de proteínas, pero puede ser normal, con VDRL no reactivo y sólo el FTA-ABS permite el diagnóstico. Nitrini señala que la prueba treponémica no reactiva en suero (FTA-ABS) virtualmente excluye la sífilis; si es reactiva y el cuadro clínico sugiere una neurosífilis, indica una punción lumbar ${ }^{5}$.

Dos de nuestros casos tenían retención de orina y uno ataxia cordonal. En la serie de Dewhurst sobre psicosis en pacientes fallecidos con neurosífilis, $5 / 18$ tenían elementos de tabes dorsal ${ }^{13}$. Dos de las psicosis eran esquizomorfas, 5 depresivas, en el resto existía una demencia.

El caso T tuvo un infarto cerebral un año antes de la demencia, el caso $\mathrm{O}$ sufrió un ataque isquémico transitorio. En ambos podría plantearse la lúes meningovascular, pero tenían factores de riesgo vascular. Un caso de Luo con infarto lacunar sin factores de riesgo vascular se clasificó como cuadro mixto, lúes meningovascular y parálisis cerebral ${ }^{14}$.

El tratamiento actual es con penicilina sódica, 18 a 24 millones U.I. diarios durante 2 o más semanas ${ }^{5,16}$. Hace 30 ó 40 años las dosis eran muy inferiores y se discutía agregar piretoterapia; se señalaba que la mejoría podía ser parcial y que no era rara una agravación secundaria ${ }^{18}$. En nuestra serie el tratamiento mejoró la sintomatología, pero todos quedaron con una demencia frontal; el mal pronóstico tendría relación con el retraso diagnóstico. En una serie en que sólo 3/43 casos volvieron a trabajar se señaló que también tenía relación con factores sociales, la capacidad cognitiva y el nivel laboral previos ${ }^{18}$.

\section{Referencias}

1. Storm-Mathiesen A. Syphilis. En Handbook of Clinical Neurology, PJ Vinken, GW Bruyn y H Klawans eds. North Holland Publ Co, Amsterdam, 1978, págs 337-94.
2. Silva C, Agar AM, Guzmán MA, Thompson L, Sepúlveda C. Neurosífilis e infección por virus de inmunodeficiencia humana. Rev Med Chile 1994; 122: 1393-7.

3. Lasso M, Balcells ME, Fernández A, Gaete P, Serri M, Pérez J, et al. Neurosífilis en pacientes portadores y no portadores de VIH: Descripción y comparación de dos cohortes históricas. Rev Chil Infect 2009; 26 (6): 540-54.

4. Méndez M y Cummings J. Dementia a clinical approach. 3th ed. 2003, Butterworth Heinemann, Philadelphia.

5. Nitrini R. Clinical and therapeutic aspects of dementia in syphilis and Lyme disease. En Handbook of Clinical Neurology, Vol. 89 (3rd series), Dementias, C Duyckaerts, I Litvan eds. Elsevier BV, 2008, págs 819-23.

6. Wilson SAK, Bruce NA. Neurosyphilis. En Neurology, 2th ed, Butterworth \& Co, London 1954. Págs 479-587.

7. Barrientos N. Aspectos actuales de la neurolúes. Estudio de 15 pacientes. Rev Chil Neuro-Psiquiat 1983; 21: 5460.

8. Rivera E, Codjambassis L, Cabello L. Neurosífilis, estudio de 19 casos en Valparaíso, Chile. Rev Chil NeuroPsiquiat 2002; 40: 253-57.

9. The ICD-10 Classification of mental and behavioural disorders. World Health Organization, Geneva, 1992.

10. American Psychiatric Association. Diagnostic and Statistical Manual of Mental Disorders: DSM-IV, 4th edition. Washington, DC: American Psychiatric Association, 1994.

11. Donoso A, Vitriol V, Fenieux CG, Quiroz M. Pseudodemencias, experiencia en un servicio de neurología. Rev Psicol (U Chile) 1992; 3: 9-17.

12. Donoso A, Figueroa C, Gómez R, Behrens MI. Demencia frontotemporal: experiencia clínica. Rev Med Chile 2009; 137: 909-14.

13. Dewhorst K. Clinico-pathological aspects of the neurosyphilitic psychoses. Postgrad med J 1968; 44: 898-902.

14. Luo W, Ouyang Z, Xu H, Chen J, Ding M, Zhang B. The clinical analysis of general paresis with 5 cases. J Neuropsychiatry Clin Neurosci 2008; 20: 490-3.

15. De la Cruz W, Castañeda M. Características clínicas y tratamiento de la neurosífilis en un hospital público, Callao 1997-2007. Rev peru med exp salud publica. 2008; 25: 369-73.

16. Teixeira AL, Malheiros JA, Lambertucci JR. Rapid progressive dementia associated with neurosyphilis. Rev Soc Bras Med Trop 2006; 39: 390-1.

17. Sethi S, Dus A, Kakkar N, Banga S, Prabhakar S, Sharma M: Neurosyphilis in a tertiary care hospital in north India. Indian J Med Res 2005; 122: 249-53.

18. Dawson-Butterworh K, Heathcote PR. Review of hospitalized cases of general paralysis of the insane. Br J Vener Dis 1970; 46: 295-302. 